\title{
JClic Crosswords in Chemistry Class
}

\author{
María de los Ángeles Montiel Montoya \\ Department of Chemistry, National Preparatory School No. 4, National Autonomous University of Mexico, Mexico 11870, Mexico
}

\begin{abstract}
Eight crosswords made in JClic were applied to twenty nine students from group 654, in area 2, at ENP (national preparatory school) No. 4 (a national public high school) in order to review Unit 2 and introduce the following Unit of Chemistry IV. Two surveys were applied in scholars in order to evaluate: the application of crosswords and of ICT (information and communications technology). The results show that students like ICT because it is a relaxing mechanism to learn, JClic games were also liked by the majority due to the team work, so it induces to considerable learning.
\end{abstract}

Key words: ICT, JClic, amusing teaching-learning activities, crosswords, organic chemistry.

\section{Introduction}

The application of ICT (information and communications technology) as an education mechanism has been very productive to the teachers that have the proper infrastructure to take advantage of them, for example science laboratories, rooms and classrooms that are equipped with a projector. That is the case of NPS (national preparatory school). Every year, more and more students are able to have a computer at home with internet access that makes it easy for them to do their homework using ICT, so the teachers can take even more advantage of technology by using it inside and outside the classroom [1].

JClic is one of the favorite tools based on ICT of EPN scholars from Chemistry III and IV, in area 2.

JClic is a program platform whose main function is the improvement of teaching-learning activities based on amusement. It was developed in Java so it can be used with Windows office and Linux platforms, which makes it a very versatile tool to be applied simply and friendly in educational activities. JClic is compatible with multimedia (videos, images, sounds, etc.) under different formats that are used in educational activities, the most common are: AVI in video, MP3 and WAV in audio, JPG, GIF, PNG and BMP in images and

\footnotetext{
*Corresponding author: María de los Angeles Montiel Montoya, bio-pharmaceutical chemist, rearch field: learning strategies. E-mail: maangel@unam.mx.
}

SWF in presentations. Images that are created out of graphic editors can be turned into the formats mentioned before. JClic has three applications: JClic Player, which is the main program and the one that executes all the activities, creating and organizing all projects in the different platforms, this is the one that is used by the students. JClic Author that creates, modifies and shows the projects, it is made of different activities with diverse multimedia files, this part is used by the professor. JClic Reports, it is independent from the others and it constructs a data base where the results of the projects are saved in order to help the professor to have more information for the evaluation process [2].

JClic main activities are: 1 . Simple associations that show two groups of information that have the same number of elements. Each image element is in correspondence with an origin element. 2. Complex association, it presents two groups of information that may not have the same number of elements which may also be related in different ways: one to one, diverse to one and elements without correspondence. The associations' objective is to find the relation between both groups, which is done by dragging with the mouse the element that wants to be proved from the group it belongs to the other group, if correspondence is found, the element disappears from one or both of the groups. 3. Memory games, designed 
to find pairs of elements that are related to each other. In each play a pair of pieces is shown and if they are not identical they disappear automatically. The purpose is to find all the pairs. The elements can be presented in texts, images, sounds and a combination of all of them. 4. Exploration activities, where an element appears and by clicking on it, some information about it is displayed. 5. Identification activities, in which a group of information is exposed and the participant has to click on those that have something in common. 6. Puzzles with two screens, one is disorganized and the other is empty. The puzzle is solved by dragging piece by piece in the correct place. 7. Exchange puzzle, in the same screen the information is mixed up; in each play two pieces are changed from its place to the correct one. 8. Space puzzle, in the same screen a piece disappears and the rest are mixed up. In each play a piece near the space can be moved, until they are all in their correct place. 9. Text: Completing the text. Some elements are missing from a text (letters, words, phrases...) and the participant must complete it. 10. Text: Filling spaces. Some words, letters or phrases are hidden from the text, when the spaces are selected, a branch of options is displayed and the correct one has to be chosen, like a multiple option exam. 11. Text: Recognition of elements. By clicking with the mouse, words, letters, numbers, symbols or punctuation signs have to be selected. 12. Text: Putting the elements in their correct place, words or paragraphs are messed up and by selecting them in the correct order, they are fixed. 13. Correct answers, groups of information are shown and for each of its elements, the correspondent text has to be written. In general, text activities are exercises based on words, phrases, letters and paragraphs of a text that has to be completed, understood, corrected or put in the correct place. Text can also show interactive images or windows. 14. Alphabet soup, the words hidden have to be found out of a grid of different letters. The boxes that do not belong to any word are filled with elements selected randomly in each play.
15. Crossword, the board has to be filled with the correct words, which have to be chosen out of their definitions that can be shown in texts, graphics or sounds; the definitions of both of the words that cross each other are shown where the cursor is. Alphabet soups and crosswords are interactive activities of hidden words.

The title of the activity of each game is shown on the top of the screen, the instructions, on the bottom of it and in front of them, three small boxes are displayed: correct answers, number of plays and time, the professor can settle limits to the plays and to the time, and the students can elevate the number of correct answers, reduce the time and the number of plays by restarting the games [3].

\section{Experimental Sections}

The Chemistry program of amusing activities that the author designed with JClic were applied during ordinary classes and in the Chemistry week, both in classrooms and in the science laboratory. Although the program has all the activities that were mentioned before, the author only selected the crosswords because students show more enthusiasm in solving this type of amusement as well as puzzles and alphabet soups. Crosswords help them to review concepts and learn new ones and also they assist on the development of reading and spelling skills because if a word is misspelled, then the boxes will not be able to be filled; another advantage out of crosswords the author was able to discover is that scholars were able to learn and analyze the periodic table (symbols and names) which were added as clues by the teacher to the ordinary ones made of common letters in the words that cross each other [4].

The results of the survey shown in this paper is based only in the application of eight crosswords that reflect the content of Unit 2 and a part of Unit 3 of the program of Chemistry IV, in area 2. These results were shown to my counterparts during the Seminar of the application of ICT that took place in "Vidal 
Castañeda y Nájera”, High school of National Autonomous University of Mexico, during the 2013-2014 courses [5].

Objectives:

(1): To motivate students in learning Chemistry in an amusing way;

(2): To review the content of Unit 2 of the program of Chemistry IV, in area 2 and to introduce Unit 3, by using JClic applications;

(3): To involve scholars in the design and elaboration of crosswords;

(4): To evaluate the educational function and use of ICT.

\subsection{Methods}

Eight crosswords were applied in order to review Unit 2: electronic energy levels, atomic orbitals, electronic configurations, Lewis structures, relationship between electronegativity and chemical bond types, hydrocarbons, alkanes, alkenes, alkines, aromatic compounds, carbon's hibridation, types of carbon-carbon connections, models and structure, nomenclature, isomerism and physic properties (two crosswords); functional groups: alcohol, ether, aldehyde, ketone, carboxylic acids, ester, amine, amide, aminoacids and compound halogens, nomenclature, structure, isomerism, properties and uses (two crosswords). Organic reactions: substitution, addition and elimination, condensation and hydrolysis, oxidation and reduction, polymerization by addition and condensation (one crossword). Unit 3 was introduced with one crossword about biomolecules, carbohydrates, lipids and proteins and one crossword with all the subjects that were reviewed and helped as an examination.

Each crossword was made out of common contents, symbols and some characteristics of the chemical elements were included as clues, so the application of the crosswords also helped to review the symbols and names of the elements of the periodic table that are not usually completely studied in the high school program.
Some crosswords were first applied to the group 654 in order to be tested in their content, the students were asked to evaluate their design and concepts and to write all their comments in a separate piece of paper, they were told to feel free to evaluate anonymously. Changes were done only in the design, use of colors and letter size. In the design, the window was expanded; colors that were used in the boxes, texts and screen were changed from dark and brilliant to light and soft, because the students asked for. The size of the letters were increased from 17 to 28 , up to 36 points so all the scholars were able to look at them when the crosswords were projected in the classrooms (with a capacity for 60 students) and also in the science laboratories, for the students to be able to see from all sights, even though they have a computer for each table of four places. After the crosswords were improved, a didactic strategy was implemented in three steps:

Introduction activities: By the end of Unit 2 of the program of Chemistry IV contents were reinforced by answering three crosswords that were produced by the professor. Those were solved in the classroom by the students and for homework they were asked to prepare their own crosswords, on a paper, with the content of Unit 2 (functional groups, chemical reactions) and of Unit 3 (biomolecules); once games were handed over, the author joined them all together in three crosswords, as the use of horizontal and vertical relations were not very used. It seems that working on paper is more difficult for them as they are used to work in the computer programs that make all the work for them. The author did not use programs to make the eight crosswords as it is a challenge for her to analyze and think the relations between the horizontal and vertical elements using only chemical symbols and strictly sticking to the subject that is to be studied.

Development activities: The crosswords made by the students were elaborated by hand and then uploaded by the teacher using JClic. Then, the crosswords were solved by the scholars in teams of 
four in the science laboratory. The program gives the number of correct answers, the mistakes as well as the timing.

Closure activities: The teacher made two crosswords specifically for examination purposes; the teams also wrote the number of correct answers, the number of plays and the timing. They were solved in the classrooms.

\section{Results and Discussion}

Two surveys were applied at the end of the activities to the 29 students of group 654, one to evaluate the didactic material and the other to grade the use of ICT. In the following sections are the results (only the most relevant ideas from the scholars were selected)

Note: Due to the participation and enthusiasm that the students showed when they solved 8 crosswords, the author decided to leave them in the computers so all the students could have access to them, during the Chemistry week, they were applied to scholars from fifth and sixth grades. More games have been added to the programs that were installed in the school computers and also to the ones in TELMEX room.

\subsection{Results}

\subsubsection{Crosswords Evaluation}

1. How did you feel with the didactic games? (Note: students $=\mathrm{a})$

Very good (11 a = 38\%);

Good (18 a = 62\%);

Bad (0\%);

Indifferent (0\%).

2. How did you participate with the team you were in?

With enthusiasm (21 a = 73\%);

Without enthusiasm ( $3 \mathrm{a}=4 \%)$; Indifferent (5 a $=17 \%)$.

Why? "As we were solving them I was able to interact with my friends". "I had a lot of fun, it was not an ordinary class". "I was able to answer all of the crosswords and reinforce my knowledge with the help of my team". "I like participating with my team with my knowledge”, "I like working by myself”.

3. The crosswords were:

Clear (17 a = 59\%);

Confusing (12 a = 41\%);

Not understood (0\%).

Why? "Questions were written correctly and the answers were related to them". "Some questions were easy and others were complicated"

4. How did you feel about working the contents of Unit 2 of the program of Chemistry IV, in area 2?

Very good (10 a = 35\%);

Good (18 a = 62\%);

Indifferent $(1 \mathrm{a}=3 \%)$.

Why? "I felt good because I was able to understand better the concepts that were not clear to me". "I got to review the functional concepts without any stress". "I reinforced every theme and that is very helpful for the preparation of evaluations".

\subsubsection{ICT Evaluation}

1. Did you like the use of ICT in an amusing way as educative mechanisms?

A lot (17 a = 59\%);

More or less $(14 \mathrm{a}=48 \%)$;

Indifferent (0\%).

Why? "Yes, they helped me a lot to better understand the themes". "Because it is didactic and you can learn more, to reinforce the themes". "The use of ICT during all the classes would be boring, but its use in some parts of it is very beneficial to reinforce the themes".

2. How often would you like ICT to be applied in Chemistry class?

Always (3 a = 10\%);

Almost always (11 a = 40\%);

Sometimes (13 a = 50\%);

Never (0\%).

Why? "It should be an extra activity. To be used at the end of each class to reinforce the knowledge of the theme seen during the lesson". "I like it because we 
can review the concepts". "You get to learn better". "A game after a theme would be good in order to reinforce it”.

\subsection{Discussion}

3.2.1 Discussion of the Crosswords' Evaluation Results

Question 1: about how they feel with the didactic games, $100 \%$ of the answers were very good or good, which reflects that the students like the didactic games. Nobody felt bad or indifferent.

Question 2: about the participation in the team, majority (73\%) was enthusiastic; the rest of them were not enthusiastic or indifferent to team work because they like better working by themselves, which was confirmed with the commentaries.

Question 3, about crosswords, the majority (59\%) thought they were clear, which reflects that they were able to answer them without difficulty, although $41 \%$ thought they were confused or complicated, the commentaries show that there is a big possibility that they did not know the answer or it was due to the movement of the cursor when they were writing the vertical answers in both ways and in the horizontal ones from left to right; nevertheless, $100 \%$ of them agreed that the crosswords were understandable.

Question 4, referring to Unit 2 and how they felt about working with crosswords, the majority (97\%) answered very good or good, only 3\% was indifferent, which means that students like answering Chemistry crosswords because it is a way to review concepts that were not clear enough or reinforce them for the preparation of their exams without feeling stressed.

\subsubsection{Discussion of the ICT's Evaluation Results}

Question 1, about the use of ICT as an educative amusing mechanism, majority (59\%) said they liked them a lot, $41 \%$ liked them more less, but nobody was indifferent, which shows that scholars like the use of ICT and games in their class because they are didactic and help them increase their learning; though, some students think that their use in all classes would be boring.

Question 2, about how often should ICT be used in Chemistry class, majority (90\%) answered almost always or sometimes in order to compete the exposition of a theme, reinforce it, or to apply them after the themes have been taught, only $10 \%$ asked for them to be used always, and as $0 \%$ did not choose never, the results show that all of the scholars agree on the use of ICT in Chemistry class.

Even though this activity is amusing and is developed in team work, proper concentration is required as some students pointed out that they were not able to write from left to right or from the bottom to the top, as they did not understand the instructions for those activities. Others said they were confused with the blinking of the cursor that showed when the answer should be written horizontally or vertically, and if they do not pay attention, the cursor can jump to another question and that is when they got confused. These defects are part of JClic software, which complicates the participation of those students without the proper reading and writing skills.

The majority of the scholars chose the affirmative answers (very good, good, much, clear, always or almost always; indifference was chosen only in questions 2 and 4, but that is not meaningful, and never was not pointed out at all.

\section{Conclusions}

Crosswords turned out to be a different way of learning and to reinforce the themes of Units 2 and 3 of the program of Chemistry IV, area 2, in an interactive and fun way, without feelings of stress, which contributed to review the themes that had already been seen during class and to learn the new themes with the direct and enthusiastic participation of the students. With the use of this activity, it is possible to increase the abilities of the scholars on reading instructions and answering crosswords in all possible directions: horizontally, from left to right, which is the 
easiest one, and from right to left; vertically, from the bottom to the top and backwards, which turned out to be more difficult and confusing for them, not just because they are not used to it, but also because the cursor changes position.

The application of the 8 crosswords, from which 2 were designed out of the ones produced by the students, was able to motivate them to study in an amusing way in Unit 2 and the introduction of Unit 3 of the program of Chemistry IV, in area 2.

The evaluation results of the amusing material (8 crosswords) went from good to very good, which shows that it is possible to learn by playing and by having fun, without feeling stressed, and that most of them like team work. The use of ICT as a didactic mechanism was approved by the students so that it means they get to stay in the classrooms and science laboratories.

Even though scholars use ICT all the time, they do not believe that they should be used as educational mechanisms during all the classes. They believe that technology should be mainly used for entertainment and fun activities; nevertheless, all of them agree that amusing activities, such as crosswords are positive for learning, reinforcing themes and studying without feeling stressed.

\section{References}

[1] Bate, A. W. 2010. The Technology in Open and Distance Education. México: Trillas.

[2] Sandra, C. M. 2013. "JClic Activities: A Didactic Resource in Technologies, Innovation and Educational Experiencies.” Accessed Jun 11, 2013. http://www.csi-csif.es/andalucia/modules/mod_ense/revis ta/pdf/Numero_28/SANDRA_CAMPANA_1.pdf.

[3] Ibn Firnas, Association Astronomical Observatory of the Rinconada. 2015. Creation of Educational Activities Multimedia Jclic, Teach Otherwise. Quick reference guide. Accessed Jul 16, 2015 http://clic.xtec.cat/does/JClic_referencia.pdf.

[4] Montiel, M. A. 1992. "The Creativity in the Games." Memories of Nacional Congress by Biochemical Teachers. Morelia: Nicolaita University.

[5] Notes of JClic Course in the ICT Seminar. 2013. National Preparatory School No. 4, National Autonomous University of Mexico, México. 